\title{
Substance Abuse Related Predictors in Soldiers' Suicidal Attempt
}

\author{
Alireza Mehrazmay, ${ }^{1}$ Mojtaba Satkin, ${ }^{1}$ Alireza Karambakhsh,,${ }^{1}$ Mahmood Salesi, ${ }^{1}$ Mozhgan Lotfi, ${ }^{2}$ and \\ Khodabakhsh Ahmadi ${ }^{1, *}$ \\ ${ }^{1}$ Behavioral Sciences Research Center, Baqiyatallah University of Medical Sciences, Tehran, IR Iran \\ ${ }^{2}$ Tehran Institute of Psychiatry, School of Behavioral Sciences and Mental Health, Iran University of Medical Sciences, Tehran, IR Iran \\ "Corresponding author: Khodabakhsh Ahmadi, Behavioral Sciences Research Center, Baqiyatallah University of Medical Sciences, Mollasadra Ave. Vanak Sq., P. O. Box: 19945581, \\ Tehran, IR Iran. Tel: +98-2182482475, Fax: +98-2188053767, E-mail: khodabakhsh.ahmadi@gmail.com
}

Received 2015 February 17; Revised 2015 October 10; Accepted 2015 November 23.

\begin{abstract}
Background: Military populations are at high risk for suicidal behavior. There are several well-known predictors for suicide and a few studies have evaluated the effect of substance abuse patterns on suicide in military environments.

Objectives: This study was designed to determine substance abuse related factors that predict suicidal attempts in soldiers by concerning confounding factors. The importance of determining these risk factors is that they allow us to identify high-risk people, who should receive intensive monitoring and attempts should be made to reduce modifiable predictors.

Patients and Methods: Through a cross sectional research, 3960 soldiers were selected by cluster sampling from army service garrisons in 12 regions of Iran during 2010. Data were gathered by demographic and military environment information, Texas Christian University (TCU) drug screen II and the Addiction Severity Index (ASI). The dependent variable was suicidal attempt during the military service course and the independent variables were demographic (age, education, job prior to service course and life situation), substance abuse related (the age at first substance abuse experience, alcohol abuse, tobacco abuse, ecstasy abuse, analgesics abuse, opium abuse, marijuana abuse, multi drug abuse and history of drug intoxication (subgroup analysis)), psychosocial (history of anxiety disorder, depression, obsessive compulsive disorder, personality disorder, child abuse, HIV risk behavior, physical fight) and military service-related factors (service place satisfaction, bad relationship with commanders, always having feelings of loneliness, combat situation, distance from home). Information was decoded in the SPSS 21 software and a backward logistic regression analysis was performed.

Results: The majority of soldiers with mean age of 21.8 ( $\mathrm{SD}=2.4$ ) years were single (82.1\%), employed (54.5\%) and had a low level of education or were illiterate (71.1\%). In total, 296 (7.5\%) soldiers had suicidal attempts in their military service course. Predictors of suicidal attempt were education level of under diploma, age of under 18, being abused during childhood, having a history of human immunodeficiency virus (HIV) high risk behavior, anxiety disorder, depression disorder and service place dissatisfaction. By controlling known confounders, substance abuse-related predictors of suicidal attempt were first experience of substance abuse before the age of $15(\mathrm{OR}=1.48, \mathrm{P}=0.023)$, abusing opium $(\mathrm{OR}=3.92, \mathrm{P}=0.000)$, alcohol $(\mathrm{OR}=1.39, \mathrm{P}=0.023)$ and multi substance abuse $(\mathrm{OR}=1.37, \mathrm{P}=0.029)$.

Conclusions: By intensive monitoring of the situation of substance abuse among soldiers, commanders can reduce modifiable predictors of suicidal attempt.
\end{abstract}

Keywords: Army, Soldiers, Behavior, Addictive, Suicide, Predictor, Risk Factors

\section{Background}

Suicide is a major problem of societies (1), and leads to approximately one million deaths annually and many complications worldwide $(2,3)$. Although religious faith and beliefs of Muslims forbids suicide (4), the nationwide rates of complete suicide in 2002 were 5.7 per 100,000 for males and 3.1 for females.

Military populations are at high risk of suicidal behavior (5) because of access to weaponry and marksmanship training, desensitization due to non-suicidal traumatic events (6) and possible self-selection of more aggressive individuals (7-9). The military personnel suicide rate per 100000 individuals has been reported by different studies:
12.2 in Canada, 13.6 in Finland, 14 in France, 13.6 in Norway, 17.3 in Poland, 30 in Russia, 11 in UK and 12.5 in the US (10).

There is a 24-month compulsory military service course for males over 18 years in Iran, during which they are considered as soldiers. Military service is a stressful course, and up to $67 \%$ of military personnel suffers from a high level of stress (11). These factors may lead to adaptive problems such as suicidal attempt, self-injury and homicide (4). There are several well known predictors of suicide which include demographic characteristics (e.g., younger age, being single, male gender, socioeconomic status and unemployment), psychiatric diseases (e.g., depressive and bipolar disorders, anxiety disorders, psychotic disorders, 
certain personality disorders, and alcohol, tobacco and drug use disorders), psychological symptoms (e.g., depression and hopelessness), biopsychosocial risk factors (e.g., suicide ideas and history of suicide attempts, family history of suicide, history of trauma or abuse, impulsive or aggressive tendencies, some major physical illnesses), environmental risk factors (e.g., job or financial loss, relational or social loss, easy access to lethal means, local clusters of suicide that have a contagious influence) and sociocultural risk factors (e.g., lack of social support and sense of isolation, stigma associated with help-seeking behavior, barriers to accessing health care (especially mental health and substance abuse treatment), certain cultural beliefs, exposure to suicide through the media, and influence of others who have died through suicide) (12-15).

Considering the high prevalence of suicide in military settings, substance abuse is an important risk factor, which has a bidirectional direct or indirect association with suicide yet there are a few studies that have evaluated the relationship between substance abuse patterns and suicide in military environments.

\section{Objectives}

This study was designed to determine substance abuserelated factors that predict suicidal attempts in soldiers by concerning confounding factors. The importance of determining these risk factors was to identify high-risk individuals who should receive intensive monitoring and to reduce modifiable predictors.

\section{Patients and Methods}

\subsection{Study Design}

A cross sectional research was conducted to evaluate substance abuse status in Iranian soldiers during year 2010.

\subsection{Participants}

The target population was soldiers in the military service course. The population was stratified to Army, Air Force and Navy soldiers. In each stratum, from 33 provinces of Iran, 12 provinces were selected as clusters and within each province, one garrison was selected. Cluster sampling was done from army service garrisons in 12 regions of Iran. Next, random sampling was done for each garrison. The inclusion criterion was being part of the military service at least for three months. Sample size was calculated considering a study power equal to $80 \%$ (beta $=0.2$ ). Finally 3960 soldiers with mean age of 21.8 years $(S D=2.4)$ were included in the study.

\subsection{Assessment Tool}

Self-reported questionnaires were administered to soldiers. Demographic information questionnaire was used to assess characteristics like age, education level, marriage status, job prior to military service course, and kinds and methods of abused substances. Texas Christian University (TCU) drug screen II was used for all soldiers for primary screening of substance abuse. Next, the Addiction Severity Index (ASI) (5th edition) was used to assess the medical, job prior to military service course, substance and alcohol abuse, legal and family and mental status of soldiers. The TCU and ASI questionnaires validity and reliability has been confirmed by previous studies $(16,17)$.

\subsection{Measures}

The dependent variable was suicidal attempt during the military service course by asking the soldiers the following question; "Did you have suicidal attempts during your military service course?"

Three groups of confounding independent variables were considered to be controlled: 1) demographic factors including age, education and job prior to service course; 2) psychosocial factors including history of anxiety disorder, depression, obsessive compulsive disorder, personality disorder, child abuse (emotional, sexual or physical), HIV high risk behavior, living without family, always experiencing feelings of loneliness during the military course (like unsafe sexual contact or intravenous drug abuse) and physical fight; 3) military service-related factors that involved service place satisfaction, bad relationship with commanders, combat situation and distance from home. The main variable, which was "substance abuse-related factors", included age of initiation, abuse of alcohol, cigarette, ecstasy, analgesics (like tramadol, narcotics and sedatives), opium, marijuana, multi substance abuse, and history of drug intoxication (subgroup analysis).

\subsection{Analysis}

The data was decoded and entered in the SPSS 21 software. Next, a backward logistic regression analysis was done, considering P values of less than 0.05 as significant.

Ethical approval was obtained on 20/9/2009 with code number 89-360. Participants' satisfaction and privacy were considered at all stages of the study.

\section{Results}

\subsection{Descriptive Statistics and Univariate Analysis}

The majority of participants were single (82.1\%), employed (54.5\%) and were illiterate or had a low level of education (71.1\%). In total, 296 (7.5\%) soldiers had suicidal attempts during their military service course. Table 1 shows 
the lifelong and military course suicidal attempt prevalence among soldiers.

Table 1. Lifelong and Military Course Suicidal Attempt Prevalence Among Soldiers ${ }^{\mathrm{a}}$

\begin{tabular}{lcc}
\hline & Lifelong & Military Course \\
\hline All Soldiers & $382(9.6)$ & $296(7.5)$ \\
Substance Abusers & $201(19.6)$ & $146(14.2)$ \\
\hline
\end{tabular}

${ }^{\mathrm{a}}$ Values are expressed as No. (\%).

The univariate analysis of the primary independent variable in relation with suicidal attemps revealed that an age below 22 years $(\mathrm{P}<0.0001)$, education under diploma $(\mathrm{P}<0.0001)$ and being unemployed $(\mathrm{P}<0.0001)$ were the demographic variables which were associated with suicidal attempt. Moreover, history of anxiety disorder ( $\mathrm{P}$ $=0.023)$, personality disorder $(\mathrm{P}<0.0001)$, depression disorder $(\mathrm{P}<0.0001)$, obsessive compulsive disorder ( $\mathrm{P}$ $=0$. 001), being abused in childhood $(\mathrm{P}<0.0001)$, history of HIV high risk behavior $(\mathrm{P}<0.0001)$, history of physical fight $(\mathrm{P}<0.0001)$, living without family $(\mathrm{P}<$ $0.0001)$ and always having feelings of loneliness during the military course $(\mathrm{P}<0.0001)$ were the psychosocial variables which were associated with suicidal attempt. Dissatisfaction with the geographic location of service $(\mathrm{P}<$ $0.0001)$, bad relationship with commanders $(\mathrm{P}<0.0001)$, and exempted combat situation $(\mathrm{P}=064)$ were the military service-related variables, which were associated with suicidal attempt. Finally, starting substance abuse at an age under 15 year $(\mathrm{P}<0.0001)$, use of alcohol $(\mathrm{P}<0.0001)$, cigarette $(\mathrm{P}<0.0001)$, ecstasy $(\mathrm{P}<0.0001)$, analgesics $(\mathrm{P}<$ $0.0001)$, opium $(\mathrm{P}<0.0001)$, marijuana $(\mathrm{P}<0.0001)$, multi substance abuse $(\mathrm{P}<0.0001)$ and history of drug intoxication (subgroup analysis) $(\mathrm{P}=0.012)$ were the substance abuse-related variables, which were associated with suicidal attempt without controlling confounders.

\subsection{Multivariate Analysis}

All independent variables contributed significantly to the final model, predicting the suicidal attempt. The results of logistic regression to determine multivariate predictors are reported in Table 2.

Soldiers who had an education level under diploma $(\mathrm{OR}=1.74, \mathrm{P}=0.009)$ and age of less than 18 years $(\mathrm{OR}=$ $1.69, \mathrm{P}=0.005$ ) were at a higher risk to attempt suicide. Also soldiers who had been abused during their childhood ( $\mathrm{OR}=3.53, \mathrm{P}=0.000)$ or had a history of HIV high-risk behavior $(\mathrm{OR}=1.41, \mathrm{P}=0.037)$, anxiety disorder $(\mathrm{OR}=1.48, \mathrm{P}=$ $0.035)$ and depression disorder $(\mathrm{OR}=2.54, \mathrm{P}=0.00)$ were at a higher risk to attempt suicide. Moreover, dissatisfaction
Table 2. Regression Analysis for the Predictors of Suicide in Soldiers

\begin{tabular}{|lccc}
\hline Variable & OR & SE & P Value \\
\hline Demographic & & & \\
\hline \multicolumn{1}{|l}{ Education under diploma } & 1.74 & 0.25 & 0.009 \\
\hline \multicolumn{1}{|l}{ Age under 22 } & 1.69 & 0.31 & 0.005 \\
\hline Substance Abuse & & & \\
\hline Opium abuse & 3.92 & 0.58 & $<0.0001$ \\
\hline Multi substance abuse & 1.37 & 0.23 & 0.029 \\
\hline Initial substance abuse before the age of & 1.48 & 0.21 & 0.023 \\
\hline 15 & & & \\
\hline Alcohol abuse & 1.39 & 0.35 & 0.023 \\
\hline Psychosocial & & & \\
\hline Child abuse history & 3.53 & 0.66 & $<0.0001$ \\
\hline HIV high risk behavior history & 1.41 & 0.30 & 0.037 \\
\hline Anxiety disorder history & 1.48 & 0.23 & 0.035 \\
\hline Depression disorder history & 2.54 & 0.41 & $<0.0001$ \\
\hline Military Service Related & & & \\
\hline Service place dissatisfaction & 1.73 & 0.25 & 0.001 \\
\hline
\end{tabular}

with the geographic location of service $(\mathrm{OR}=1.73, \mathrm{P}=0.001)$ increased the chance of suicidal attempt.

Substance abuse initiation before the age of 15 (OR = $1.48, \mathrm{P}=0.023)$, abusing opium $(\mathrm{OR}=3.92, \mathrm{P}=0.000)$, alcohol $(\mathrm{OR}=1.39, \mathrm{P}=0.023)$ and multi substance abuse (OR $=1.37, \mathrm{P}=0.029)$ increased the chance of suicidal attempt in soldiers.

\section{Discussion}

According to the results of this study, significant confounders which had been controlled were education level being below diploma and age under 22, having been abused during childhood, having a history of HIV high risk behavior, anxiety disorder, depression disorder, and dissatisfaction with the geographic area of service. The substance abuse related predictors like alcohol abuse, opium abuse and initial substance abuse before the age of fifteen and multi substance abuse increased the chance of suicidal attempt in soldiers.

Opium abuse (followed by "alcohol" in substance abuse-related factors and "child abuse history" in all factors) was the strongest predictor of suicidal attempt. Among other substances, cigarette, ecstasy and analgesics were not significant in the final model (unlike in the univariate analysis), and heroin, methamphetamine, methadone, steroids and LSD had very low reported prevalence to be analyzed. We also showed that multi substance 
users had a higher chance of suicide attempt. This has been confirmed by previous studies, which have demonstrated that the number of substances has a graded relationship with suicide (16), and is more important than the types of substances (17). This may be due to more severe stressors and psychological trauma, which trigger these people to use several substances for relief. Wong et al. showed in their study during 2013 on 73183 American high school students that adolescents who had a history of heroin abuse had the strongest association with suicidal ideas, plans, attempts and severe attempts in the most recent year. They also showed that cocaine, ecstasy, hallucinogens and inhalants, alcohol, marijuana and tobacco had an association with suicide. By multivariate analysis to control confounders, the association between each of the ten substances and the four measures of suicide remained significant, except between alcohol abuse and severe suicide attempts (16). The study of Borges et al. showed that alcohol and drug use are predictors of suicide attempts by controlling for socio-demographics and comorbid mental disorders. They also demonstrated that abuse and dependence to alcohol, inhalants, and heroin were significant predictors (17). Pawlak et al. showed that in bipolar and unipolar affective disorders, psychoactive substance abuse or dependence increases suicide attempts (18) and Sher et al. found that acute alcohol use increases the lethality of suicide attempts in individuals with mood disorders (19). Nojomi showed that lifelong use of tobacco and alcohol are independent predictors of suicide attempt (20).

We showed that substance abuse initiation before the age of fifteen is a risk factor of suicidal attempt. Other studies have demonstrated a relationship between earlier start to using hard drugs, early smoking and preteen alcohol use initiation and suicide ideation and attempt (21-24). Results of suicide attempts due to early onset of marijuana or other drug use have been mixed $(25,26)$.

We showed that history of drug intoxication (in the drug abuser subgroup) was associated with suicide attempt in the univariate analysis. Carter et al. showed in their study in 2005 that patients who have escalating severity of self-poisoning episodes are at high risk of completed suicide (27).

We showed that unemployment is a predictor of suicidal attempt, which confirms the other studies results (2833).

Our study population was all males so we didn't assess the gender factor as a predictor of suicidal attempt, yet previous studies have reported that suicide was higher in the male gender $(13,30,34)$ compared to the female gender $(20$, 28). Mahon showed that in regular-duty military personnel, male gender increases the risk of suicide (10).

In our study there was no relationship between marital status and suicide. Previous studies have shown that marriage protects men and women against suicide; and being widowed, divorced/separated and particularly unmarried is associated with a higher suicide rate (35-37).

Our population age range was limited to 17 to 37 -yearolds. We showed that an age of less than 22 is a predictor of suicidal attempt, which confirms prior reports of higher risk of suicide in younger age groups (30,38-40). Lecrubier states that suicidal ideation and attempts show parallel onset curves peaking between the ages of 14 and 20 years (41).

Our univariate analysis showed that educational level of under diploma was associated with higher suicidal attempt. Some studies have suggested that a lack of literacy is an important risk factor of suicide attempt $(42,43)$.

Child abuse history was a predictor of suicidal attempt during the military course in our study. This confirmed the results reported by Wilcox et al. which showed that childhood or adolescent exposure to domestic violence is a risk factor for persistent suicide ideation (44). Regarding the interpersonal theory of suicide, non-suicidal selfinjury and traumatic experiences like child abuse and combat exposure, have a desensitizing impact on pain and fear of self-destruction, so suicidal behavior would be more likely (6). Moreover, Undheim and Sund showed that being bullied is a predictor of later suicidal ideation (in both genders), especially individuals with high levels of depression (45)

Another predictor of suicidal attempt in our study was having a history of HIV high-risk behavior. Many studies have shown that dysfunctional impulsivity (46) and higher level of behavioral impulsivity are risk factors for suicide (47).

History of anxiety disorder and depression disorder were predictors of suicidal attempt in this study. These factors may be the complications of a disorganized family and history of child abuse or child neglect. Other studies have reported many psychosocial and psychiatric risk factors including maternal depression, high self reported depressive symptoms (44), mental disorders and high hopelessness, negative life events, suicide history in the family, lack of positive coping skills, lack of social support (46), family history of psychiatric disorders, affective disorders, inappropriate guilt in depression, chronic insomnia and early onset of unipolar disorder (18), the suicidal death of a friend (48), family conflicts (49), previous attempted suicide and comorbid disorders, including anxiety (50). Pirkis showed in their study in 2004 on 668 individuals (aged 18 to 45 years) with a diagnosed personality disorder or major depressive disorder that among the Axis II disorders, only borderline personality disorder (BPD) was a significant predictor of suicide attempts and among the Axis I disorders, only drug use disorder was a significant predictor 
of suicide attempts. Considering some confounding variables such as BPD diagnosis, worsening of major depressive disorder, drug and alcohol use have been identified as significant predictors of suicide attempt (51).

We showed that dissatisfaction with the geographic location of service was a predictor of suicide attempt. Other studies have reported higher exposure to combat and morning duty (1), military job stress (52) and decreased capacity of adaptation to military services (53) as risk factors of suicide.

This study had some limitation such as low sample size for several substance subgroups and assessment of only suicidal attempt. Therefore, future studies with a greater sample number and more suicide-associated measures can clarify ambiguities associated with this subject.

\subsection{Conclusion}

Substance abuse-related predictors like alcohol abuse, opium abuse, initial substance abuse below the age of 15 , and multi-substance abuse increased the chance of suicidal attempt in soldiers. By screening and controlling the modifiable factors, commanders can reduce the risk of suicide attempt.

\section{Acknowledgments}

This research was supported by a grant from the Baqiyatallah University of Medical Sciences, Tehran, Iran. We gratefully acknowledge the grantors and all those who helped us in this research.

\section{Footnotes}

Authors' Contribution: Mojtaba Satkin, Alireza Karambakhsh, Mahmood Salesi and Mozhgan Lotfi contributed to analysis and interpretation of data, statistical analysis and critical revision of the article; Alireza Mehrazmay contributed to provision, collection and assemblage of the study data and writing of the manuscript; Khodabakhsh Ahmadi contributed to critical revision and final approval of the study.

Financial Disclosure: Authors declare that there was no financial disclosure in the current study.

Funding/Support: This study was supported by a grant from the Baqiyatallah University of Medical Sciences and by a teaching and research scholarship from the behavioral sciences research center (Khodabakhsh Ahmadi).

\section{References}

1. Bryan CJ, Hernandez AM, Allison S, Clemans T. Combat exposure and suicide risk in two samples of military personnel. J Clin Psychol. 2013;69(1):64-77. doi: 10.1002/jclp.21932. [PubMed: 23070894].

Int J High Risk Behav Addict. 2017; 6(1):e27979.
2. Robinson K. Mental Health: Facing the Challenges, Building Solutions. Int J Migr Health Soc Care. 2006;2(2):46-7.

3. Fine T. Substance Abuse and Suicide Prevention: Evidence and Implications. DIANE Publishing; 2010.

4. Ashtiani F, Sajadechi A. Psychological Assessment of the Soldiers of Material and Logistics Command of a Military Unit. Journal Mil Med. 2005;7(2):153-9.

5. Kuehn BM. Soldier suicide rates continue to rise: military, scientists work to stem the tide. JAMA. 2009;301(11):1111. doi: 10.1001/jama.2009.342. [PubMed: 19293405] 1113.

6. Van Orden KA, Witte TK, Cukrowicz KC, Braithwaite SR, Selby EA, Joiner TJ. The interpersonal theory of suicide. Psychol Rev. 2010;117(2):575600. doi: 10.1037/a0018697. [PubMed: 20438238].

7. Malkiel BG. Fama, Efficient capital markets: A review of theory and empirical work. J Finance. 1970;25(2):383-417.

8. Shahri A, et al. . RoboCupRescue 2009-Robot League Team MRL Rescue Robot (Iran).. Azad University of Qazvin. 2009.

9. Karambakhsh A, Afshar A, Malekinejad P. Corrosion resistance and color properties of anodized Ti-6Al-4V.Journal of materials engineering and performance. 2012;21(1):121-7.

10. Mahon MJ, Tobin JP, Cusack DA, Kelleher C, Malone KM. Suicide among regular-duty military personnel: a retrospective case-control study of occupation-specific risk factors for workplace suicide. Am J Psychiatry. 2005;162(9):1688-96. doi: 10.1176/appi.ajp.162.9.1688. [PubMed: 16135629].

11. Azad-Marzabadi E, Salimi SH. Study on job stress in a military unit. J Mil Med. 2005;6(4):279-84.

12. Wenzel A, Berchick ER, Tenhave T, Halberstadt S, Brown GK, Beck AT. Predictors of suicide relative to other deaths in patients with suicide attempts and suicide ideation: a 30-year prospective study. J Affect Disord. 2011;132(3):375-82. doi: 10.1016/j.jad.2011.03.006. [PubMed: 21481944].

13. Bramness JG, Walby FA, Hjellvik V, Selmer R, Tverdal A. Self-reported mental health and its gender differences as a predictor of suicide in the middle-aged. Am J Epidemiol. 2010;172(2):160-6. doi: 10.1093/aje/kwq091. [PubMed: 20519262].

14. scholar google . 2014. Available from: http://scholar.google.com/ scholar?hl=fa\&q=bg\&btnG=.

15. Tabachnick BG, Fidell LS. Using multivariate statistics. 2001

16. Wong SS, Zhou B, Goebert D, Hishinuma ES. The risk of adolescent suicide across patterns of drug use: a nationally representative study of high school students in the United States from 1999 to 2009. Soc Psychiatry Psychiatr Epidemiol. 2013;48(10):1611-20. doi:10.1007/s00127013-0721-z. [PubMed: 23744443].

17. Borges G, Walters EE, Kessler RC. Associations of substance use, abuse, and dependence with subsequent suicidal behavior. Am J Epidemiol. 2000;151(8):781-9. [PubMed: 10965975].

18. Pawlak J, Dmitrzak-Weglarz M, Skibinska M, Szczepankiewicz A, Leszczynska-Rodziewicz A, Rajewska-Rager A, et al. Suicide attempts and clinical risk factors in patients with bipolar and unipolar affective disorders. Gen Hosp Psychiatry. 2013;35(4):427-32. doi: 10.1016/j.genhosppsych.2013.03.014. [PubMed: 23643033].

19. Sher L, Oquendo MA, Richardson-Vejlgaard R, Makhija NM, Posner $\mathrm{K}$, Mann JJ, et al. Effect of acute alcohol use on the lethality of suicide attempts in patients with mood disorders. J Psychiatr Res. 2009;43(10):901-5. doi: 10.1016/j.jpsychires.2009.01.005. [PubMed: 19246050].

20. Nojomi M, Malakouti SK, Bolhari J, Poshtmashhadi M. A predictor model for suicide attempt: evidence from a population-based study. Arch Iran Med. 2007;10(4):452-8. [PubMed: 17903049].

21. Cho H, Hallfors DD, Iritani BJ. Early initiation of substance use and subsequent risk factors related to suicide among urban high school students. Addict Behav. 2007;32(8):1628-39. doi: 10.1016/j.addbeh.2006.11.017. [PubMed: 17210230]. 
22. Swahn MH, Bossarte RM. Gender, early alcohol use, and suicide ideation and attempts: findings from the 2005 youth risk behavior survey. $J$ Adolesc Health. 2007;41(2):175-81. doi: 10.1016/j.jadohealth.2007.03.003. [PubMed:17659222].

23. Swahn MH, Bossarte RM, Ashby JS, Meyers J. Pre-teen alcohol use initiation and suicide attempts among middle and high school students: findings from the 2006 Georgia Student Health Survey. Addict Behav. 2010;35(5):452-8. doi: 10.1016/j.addbeh.2009.12.017. [PubMed: 20089362].

24. Fergusson DM, Woodward LJ, Horwood LJ. Risk factors and life processes associated with the onset of suicidal behaviour during adolescence and early adulthood. Psychol Med. 2000;30(1):23-39. [PubMed: 10722173].

25. Kelly TM, Cornelius JR, Clark DB. Psychiatric disorders and attempted suicide among adolescents with substance use disorders. Drug Alcohol Depend. 2004;73(1):87-97. [PubMed:14687963].

26. Lynskey MT, Glowinski AL, Todorov AA, Bucholz KK, Madden PA, Nelson EC, et al. Major depressive disorder, suicidal ideation, and suicide attempt in twins discordant for cannabis dependence and earlyonset cannabis use. Arch Gen Psychiatry. 2004;61(10):1026-32. doi: 10.1001/archpsyc.61.10.1026. [PubMed: 15466676].

27. Carter G, Reith DM, Whyte IM, McPherson M. Repeated self-poisoning: increasing severity of self-harm as a predictor of subsequent suicide. Br J Psychiatry. 2005;186:253-7. doi: 10.1192/bjp.186.3.253. [PubMed: 15738507].

28. Wolthuis AM, Penninckx F, Cornille JB, Fieuws S, D'Hoore A. Recurrent symptoms after stapled haemorrhoidopexy and the impact on patient satisfaction after a minimum of 2 years follow-up. Acta Chir Belg. 2012;112(6):419-22. [PubMed: 23397822].

29. Koutourousiou M, Gardner PA, Fernandez-Miranda IC, Paluzzi A, Wang EW, Snyderman $\mathrm{CH}$. Endoscopic endonasal surgery for giant pituitary adenomas: advantages and limitations. J Neurosurg. 2013;118(3):621-31. doi: 10.3171/2012.11.JNS121190. [PubMed: 23289816].

30. Kline GA, Pasieka JL, Harvey A, So B, Dias VC. Medical or surgical therapy for primary aldosteronism: post-treatment follow-up as a surrogate measure of comparative outcomes. Ann Surg Oncol. 2013;20(7):2274-8. doi: 10.1245/s10434-013-2871-3. [PubMed: 23504117].

31. Ripa RS, Jorgensen E, Kastrup J. Clinical outcome after stem cell mobilization with granulocyte-colony-stimulating factor after acute ST-elevation myocardial infarction: 5-year results of the STEMMI trial. Scand J Clin Lab Invest. 2013;73(2):125-9. doi: 10.3109/00365513.2012.750010. [PubMed: 23281844].

32. Taber DJ, Pilch NA, Meadows HB, McGillicuddy JW, Bratton CF, Chavin $\mathrm{KD}$, et al. The impact of cardiovascular disease and risk factor treatment on ethnic disparities in kidney transplant. J Cardiovasc Pharmacol Ther. 2013;18(3):243-50. doi: 10.1177/1074248412469298. [PubMed: 23258931].

33. Nojomi M, Malakouti SK, Bolhari J, Hakimshooshtari M, Fleischmann A, Bertolote JM. Epidemiology of suicide attempters resorting to emergency departments in Karaj, Iran, 2003. Eur J Emerg Med. 2008;15(4):221-3. doi: 10.1097/MEJ.0b013e3282f4d12a. [PubMed: 19078819].

34. Ekstrom MP, Hermansson AB, Strom KE. Effects of cardiovascular drugs on mortality in severe chronic obstructive pulmonary disease. Am J Respir Crit Care Med. 2013;187(7):715-20. doi: 10.1164/rccm.2012081565OC. [PubMed: 23328521].

35. Chen SY, Wu N, Gulseth M, LaMori J, Bookhart BK, Boulanger L, et al. One-year adherence to warfarin treatment for venous thromboembolism in high-risk patients and its association with long-term risk of recurrent events. J Manag Care Pharm. 2013;19(4):291-301. [PubMed: 23627575].

36. Casey P, Gemmell I, Hiroeh U, Fulwood C. Seasonal and sociodemographic predictors of suicide in Ireland: a 22 year study. J Affect Disord. 2012;136(3):862-7. doi: 10.1016/j.jad.2011.09.020. [PubMed: 22018639].
37. Urena M, Rodes-Cabau J, Freixa X, Saw J, Webb JG, Freeman M, et al. Percutaneous left atrial appendage closure with the AMPLATZER cardiac plug device in patients with nonvalvular atrial fibrillation and contraindications to anticoagulation therapy. J Am Coll Cardiol. 2013;62(2):96-102. doi: 10.1016/j.jacc.2013.02.089. [PubMed 23665098]

38. Honeycutt GR, Safdar Z. Pulmonary hypertension complicated by pericardial effusion: a single center experience. Ther Adv Respir Dis. 2013;7(3):151-9. doi: 10.1177/1753465812471416. [PubMed: 23258502].

39. Wray J, Frigiola A, Bull C, Adult Congenital Heart disease Research $\mathrm{N}$. Loss to specialist follow-up in congenital heart disease; out of sight, out of mind. Heart. 2013;99(7):485-90. doi: 10.1136/heartjnl2012-302831. [PubMed: 23257171].

40. Antypa N, Antonioli M, Serretti A. Clinical, psychological and environmental predictors of prospective suicide events in patients with Bipolar Disorder. J Psychiatr Res. 2013;47(11):1800-8. doi: 10.1016/j.jpsychires.2013.08.005. [PubMed: 24018102].

41. Lecrubier Y. The influence of comorbidity on the prevalence of suicidal behaviour. Eur Psychiatry. 2001;16(7):395-9.

42. Rakhra SS, Lee M, Iyengar AJ, Wheaton GR, Grigg L, Konstantinov IE, et al. Poor outcomes after surgery for coarctation repair with hypoplastic arch warrants more extensive initial surgery and close longterm follow-up. Interact Cardiovasc Thorac Surg. 2013;16(1):31-6. doi: 10.1093/icvts/ivs301. [PubMed: 23059853]

43. Khader A, Farajallah L, Shahin Y, Hababeh M, Abu-Zayed I, Kochi A, et al. Cohort monitoring of persons with diabetes mellitus in a primary healthcare clinic for Palestine refugees in Jordan. Trop Med Int Health. 2012;17(12):1569-76. doi:10.1111/j.1365-3156.2012.03097.x. [PubMed: 23051859].

44. Wilcox HC, Arria AM, Caldeira KM, Vincent KB, Pinchevsky GM, O'Grady KE. Prevalence and predictors of persistent suicide ideation plans, and attempts during college. J Affect Disord. 2010;127(1-3):28794. doi: 10.1016/j.jad.2010.04.017. [PubMed: 20471691].

45. Undheim AM, Sund AM. Involvement in bullying as predictor of suicidal ideation among 12-to 15-year-old Norwegian adolescents. Eur Child Adolesc Psychiatry. 2013;22(6):357-65. doi: 10.1007/s00787-012-0373-7. [PubMed: 23361192].

46. Zhang J, Li N, Tu XM, Xiao S, Jia C. Risk factors for rural young suicide in China: a case-control study. J Affect Disord. 2011;129(1-3):244-51. doi: 10.1016/j.jad.2010.09.008. [PubMed: 20880593].

47. Wojnar M, Ilgen MA, Czyz E, Strobbe S, Klimkiewicz A, Jakubczyk $A$, et al. Impulsive and non-impulsive suicide attempts in patients treated for alcohol dependence. J Affect Disord. 2009;115(1-2):131-9. doi: 10.1016/j.jad.2008.09.001. [PubMed:18835498].

48. Bartik W, Maple M, Edwards H, Kiernan M. The psychological impact of losing a friend to suicide. Australas Psychiatry. 2013;21(6):545-9. doi: 10.1177/1039856213497986. [PubMed: 23897736].

49. Nazarzadeh M, Bidel Z, Ayubi E, Asadollahi K, Carson KV, Sayehmiri K. Determination of the social related factors of suicide in Iran: a systematic review and meta-analysis. BMC Public Health. 2013;13:4. doi: 10.1186/1471-2458-13-4. [PubMed: 23289631].

50. Hawton K, I Comabella CC, Haw C, Saunders K. Risk factors for suicide in individuals with depression: a systematic review. J Affect Disord 2013;147(1-3):17-28. doi: 10.1016/j.jad.2013.01.004. [PubMed: 23411024].

51. Pirkis JE. Borderline personality disorder, drug use disorder, and worsening depression or substance abuse are significant predictors of suicide attempts in people with Axis I and II disorders. Evidencebased mental health. 2004;7(1):25-6.

52. Logan J, Skopp NA, Karch D, Reger MA, Gahm GA. Characteristics of suicides among US army active duty personnel in 17 US states from 2005 to 2007. Am J Public Health. 2012;102 Suppl 1:S40-4. doi: 10.2105/AJPH.2011.300481. [PubMed: 22390599].

53. Afshar A, Yari M, Karambakhsh A. The Effect of Anodizing Voltages on Properties of the Colored Ti-6Al-4V Alloy. 2008 